\title{
Relative contribution of agroforestry, rainforest and openland to local and regional bee diversity
}

\author{
Patrick Hoehn • Ingolf Steffan-Dewenter • Teja Tscharntke
}

Received: 7 May 2009/Accepted: 5 March 2010/Published online: 19 March 2010

(C) The Author(s) 2010. This article is published with open access at Springerlink.com

\begin{abstract}
Due to increasing human modification of tropical landscapes, the relative importance of natural habitats and agricultural systems has become a major conservation topic to counteract global species loss. We investigated the contribution of tropical primary forest, cacao agroforestry systems of varying management practices and openland to the temporal and spatial variation of diversity of native bee communities in the herb layer (Apidae, Hymenoptera) in Sulawesi (Indonesia). Local bee density and diversity were highest in openland, followed by agroforestry systems and were lowest in primary forests, revealing the importance of herbaceous food resources in the understorey. In contrast, highest regional bee richness was found in agroforestry systems, because of high community dissimilarity. Multidimensional scaling supported these findings with openland habitats showing more compactly clustered bee species communities than agroforestry habitats. In conclusion, the herb associated bee community profited from the opening of the landscape as a result of agricultural activities, while agroforestry systems increased bee species richness especially on a regional scale due to high management diversity.
\end{abstract}

Keywords Additive partitioning - Apidae · Biodiversity · Conservation ·

Sulawesi · Land-use gradient · Pollinator community

More than $50 \%$ of the world's forests have been lost, mostly due to expanding agricultural land. This trend is ongoing in $70 \%$ of the countries worldwide (MEA 2005). Deforestation is threatening global biodiversity especially in biodiversity hotspots such as tropical SE

\footnotetext{
P. Hoehn $(\bowtie)$

eurofins-GAB, Eutinger Strasse 24, 75223 Niefern-Öschelbronn, Germany

e-mail: pathoehn@web.de; patrick.hoehn@eurofins-gab.com

I. Steffan-Dewenter

Population Ecology Group, Department of Animal Ecology I, University of Bayreuth,

Universitätsstrasse 30, 95447 Bayreuth, Germany

P. Hoehn - T. Tscharntke

Agroecology, University of Göttingen, Waldweg 26, 37073 Gottingen, Germany
} 
Asia (Groombridge 1992; Castelletta et al. 2000; Giri et al. 2003). Many species can utilize both native and agricultural habitats, as shown for moths and mammals in the Neotropics (Ricketts et al. 2001; Daily et al. 2003). Anthropogenic habitats might therefore be considered in conservation planning to reduce biodiversity loss (Daily 2001; Tscharntke et al. $2005 \mathrm{a}, \mathrm{b})$. In particular coffee and cacao agroforestry, two globally important agricultural systems, receive growing attention for their potential in conservation of biodiversity (Perfecto et al. 1996; Klein et al. 2002; Tylianakis et al. 2006; Perfecto et al. 2007; SteffanDewenter et al. 2007). They can provide appropriate surrogate habitats for many forest species, but the composition of these habitats is crucial for the maintenance of a native species community (Dietsch et al. 2007). Agroforestry systems include a range of different land-use intensities, from a diverse shade tree community containing primary forest tree species and a dense canopy cover to plantations with only a few planted shade tree species and low canopy cover (Perfecto et al. 2007). High biodiversity in agricultural landscapes is particularly important for the maintenance of ecosystem services, such as pollination (Kremen et al. 2002; Klein et al. 2003a; Ricketts et al. 2008) and the most important taxon performing this ecosystem service is the family Apidae (Klein et al. 2007). As the European honeybee (Apis mellifera L.) is declining world wide, there is an increasing reliance on diverse wild bee communities for pollinating cash crops (Kearns et al. 1998; Klein et al. 2003a; Kremen et al. 2004; Klein et al. 2007).

Studies relating the influence of disturbance and land-use intensity in different habitats to bee species composition apparently reach opposite conclusions. Agricultural intensification leads to reduced species richness and abundance of the native bee community in North American watermelon fields (Kremen et al. 2002), and high anthropogenic disturbance lowered species richness of stingless bees in tropical forest habitats (Cairns et al. 2005). In contrast, bee species richness increased with decreasing forest cover in the landscape and was highest in agricultural fields compared to extensive forest, which resemble the natural habitat in a pine oak heath in a study of Winfree et al. (2007). Similarly, bee species richness was higher in disturbed forests, compared to primary forest, in tropical Southeast Asia (Liow et al. 2001). Comparative studies of a broad range of habitats along a land-use intensification gradient from primary forests, managed agroforestry systems differing in land-use intensity to openland, and their relative importance for bee species richness are missing, but required to clarify these mixed results. In this study, we hypothesized agroforestry systems to increase species richness and density of bees compared to primary forest due to increased floral density of herbs (including cash crops) and high management diversity. Furthermore, agroforestry systems might maintain higher species richness and density compared to openland, because forested habitats with open canopy offer both floral rewards and suitable nesting sites for wood-nesting bee species (Klein et al. 2003b).

\section{Methods}

Study regions and study site

The study was conducted in the Lore Lindu National Park in Central Sulawesi (Indonesia) $100 \mathrm{~km}$ south of the region's capital Palu. Study sites were located in an area of agricultural activity surrounding the village of Toro $\left(120^{\circ} 2^{\prime} \mathrm{E}, 1^{\circ} 30^{\prime} \mathrm{S}, 800-1100 \mathrm{~m}\right.$ asl $)$ and in the primary forest where the village is embedded in. The landscape covers a mosaic of different habitats, from undisturbed primary and disturbed tropical forests to cacao agroforestry systems of differing management intensity and open habitats such as grasslands, 
pastures and paddy fields. We surveyed five different habitat types in our study region, comprising a range of environmental conditions. The five habitat types were primary forest $(\mathrm{PF})$, three different management intensities of cacao agroforestry and openland such as grassland and fallow land (OL) with only few trees. We refer to a plot as a site with homogeneous land-use practices of the mentioned habitat type and with a minimum core area of $30 \times 50 \mathrm{~m}$. The cacao agroforestry systems formed a gradient according to the composition of shade tree species and associated canopy cover: LIA = low management intensity agroforestry with natural forest trees as shade trees. MIA = medium-intensity systems with a diverse shade tree community entirely planted by farmers. HIA $=$ highintensity agroforestry plots with few planted shade tree species, mainly Gliricidia sepium (Jacq.) and Erythrina subumbrans (Hassk.). Forest distance $(m)$ was not significantly different between habitat types $\left(r^{2}=0.12, F_{3,11}=0.5, P=0.69\right.$; OL: $113.5 \pm 8.6$, $n=3$; HIA: $93.3 \pm 9.9, n=4$; MIA: $115.3 \pm 10.5, n=4$; LIA: $105.8 \pm 18.9, n=4$ ). Four replicates were chosen for each habitat type, but we were forced to abandon one primary forest plot and one openland plot. Extensive agricultural activities in these two plots, such as clear cutting and corn cultivation, fundamentally changed the habitat character. Canopy cover was measured with a spherical densiometer (Model-C, Robert E. Lemmon, Forest Densiometers, 5733 SE Cornell Dr., Bartlesville, OK 74006) in one meter height from two persons independently at twelve positions within each plot and varied between habitats (primary forest plots: $90.9 \pm 5.1 \%, n=3$; low-intensity plots: $90.5 \pm 1.9 \%, n=4$; medium-intensity plots: $85.5 \pm 4.7 \%, n=4$; high-intensity plots: $78.3 \pm 6.5 \%, n=4$ and openland: $16.3 \pm 11.2 \%, n=3$ ). Between cacao and shade trees farmers grew a variety of cash crops. Aubergine (Solanum melongena L.), chilli (Capsicum annuum L.), clove (Syzygium aromaticum L.), coffee (Coffea robusta Lind.), cucumber (Cucumis sativus L.), curcuma (Curcuma domestica Vahl.), pineapple (Ananas comosus (L.) Merr.), pumpkin (Cucurbita moschata Duch. ex Poir.), tapioca (Manihot esculenta Crantz.), tomato (Solanum lycopersicum L.) and vanilla (Vanillia planifolia Andr.) are among the most frequently planted crops contributing to the floral diversity within the plots. Furthermore, agroforestry systems passed a variety of agricultural activities throughout the year and differed in plot history. Both aspects contributed to the management diversity of agroforestry systems (Table 1).

\section{Sampling of bee diversity}

Bees (Hymenoptera: Apiformes) were recorded during the morning between 10:30 and 12:00 a. $\mathrm{m}$. in a standardized way along six random transects each $4 \mathrm{~m}$ wide and $30 \mathrm{~m}$ long. Sampling was conducted by sweep netting in the herb layer and the understorey of the forested plots. Each bee was caught if possible and the visited plant was noted. We additionally caught slow flying bees, which were searching for flowers, but we did not consider fast passing bees, as they may be 'tourists' that do not belong to the plot specific apifauna. To account for temporal species turnover, we conducted five sampling phases with each plot visited once per phase: 1: 22 March 2005-20 April 2005, 2: 26 April 200503 June 2005, 3: 08 June 2005-21 July 2005, 4: 10 January 2006-09 February 2006 and 5: 28 February 2006-17 March 2006. Bee species were identified by Stephan Risch from Leverkusen, Germany. Voucher specimens are kept at the Bogor Agricultural University (IPB) in Indonesia. Density of each flowering plant species and flower diversity in the herb layer and understorey were recorded subsequent to each transect walk. Flower density of each plant species per transect was estimated, using a scale between one, equivalent to a single flower of one species, and 100 for a species that covers the whole area with flowers. 
Table 1 Management diversity of openland and agroforestry systems (habitat codes described in methods) in terms of plot history (former plantation) and land-use practices in 2005

\begin{tabular}{|c|c|c|c|}
\hline Habitat/replicate & Former plantation & Fertilizer & $\begin{array}{l}\text { Herb layer removal } \\
\text { (times per year) }\end{array}$ \\
\hline OL1 & Paddy & Nothing & Mechanical $(3 \times)$ \\
\hline OL2 & Paddy & Nothing & Mechanical $(2 \times)$ \\
\hline OL3 & Paddy & Nothing & Mechanical $(3 \times)$ \\
\hline LIA1 & $\begin{array}{l}\text { Coffee and } \\
\text { sugar palm }\end{array}$ & Litter ash & Mechanical $(3 \times)$ \\
\hline LIA2 & Coffee & Nothing & Mechanical $(4 \times)$ \\
\hline LIA3 & Coffee & Nothing & Mechanical $(1 \times)$ \\
\hline LIA4 & Coffee & Nothing & Mechanical (n. s.) \\
\hline MIA1 & Unknown & Litter ash & Mechanical $(25 \times)$ \\
\hline MIA2 & Primary forest & Nothing & Mechanical $(4 \times)$ \\
\hline MIA3 & Clove & Rotting litter & Mechanical $(4 \times)$ \\
\hline MIA4 & $\begin{array}{l}\text { Coffee, clove, peanut, } \\
\text { corn and others }\end{array}$ & KCL and Urea & $\begin{array}{l}\text { Mechanical and } \\
\text { chemical }(3 \times)\end{array}$ \\
\hline HIA1 & Coffee & Nothing & Mechanical $(4 \times)$ \\
\hline HIA2 & Corn & $\begin{array}{l}\text { Urea and } \\
\text { Triplesuperphosphate }\end{array}$ & $\begin{array}{l}\text { Mechanical and } \\
\text { chemical }(3 \times)\end{array}$ \\
\hline HIA3 & Paddy & Nothing & Mechanical $(4 \times)$ \\
\hline HIA4 & Homegarden & Urea and Triplesuperphosphate & Mechanical $(3 \times)$ \\
\hline
\end{tabular}

The six transect walks per observation morning and plot covered almost half of the plot core area $\left(720 \mathrm{~m}^{2}\right)$. Plant species were identified with the help of Dr. Ramadhanil Pitopang from the Herbarium Celebense at the Tadulako University in Palu (Indonesia) using the local collection and library. For standardization we conducted transect walks only on sunny and calm days, but to test for the effect of minor daily climatic differences on bee species composition, we recorded temperature, humidity and light intensity. Measurements were done at the beginning, in the middle and at the end of each observation morning and then averaged. We used a thermo-, hygro- and luxmeter (Mavalux Digital, Gossen) at a height of $2 \mathrm{~m}$ in the centre of the plot. Temperature and humidity were measured in the shadow and light intensity in an area receiving full sun. Furthermore we measured the slope of each plot with a clinometer (Suunto PM-5/360 PC) at four distances within each plot and afterwards calculated the average.

\section{Statistical analysis}

In a Spearman's rank correlation matrix, temperature, humidity and light intensity were collinear (temperature and humidity: $N=86, R=-0.86$, *** $P<0.001$; temperature and light intensity: $N=67, R=0.45$, *** $P<0.001$; humidity and light intensity: $N=66, R=-0.47$, *** $P<0.001$ ). We therefore used a PCA to reduce the total number of variables and extract one main factor (from now on: "climate"), explaining $75 \%$ of the total variance to be used as a continuous predictor in the following analysis. We conducted two general linear models (GLM) to identify the factors that structure the pollinator community. The models included number of bee species and number of bee individuals as response variables (log transformed), habitat type and phase as categorical predictors and climate and number and density of flowering plant species as continuous variables. Due to 
collinearity of density and species richness of flowering plants, we alternated the order of both continuous predictors. Because samples from the same plot in different seasons (phases) were non-independent, plot and phase were included as random effects and plot was nested in habitat type. Post-hoc tests for differences between habitat types used Tukey's unequal N HSD (Honestly Significant Difference) test. Values per plot and sampling phase of response and predictor variables were used for the statistical analyses. To test whether plant density depends on canopy cover or other plot variables, we conducted a general linear model with plant density as response variable and canopy cover, slope and plot altitude as continuous predictors.

We estimated species richness using Michaelis-Menten means (Colwell and Coddington 1994) for each habitat type independent of sample size and calculated the percentage of recorded species from the estimated number of species. We randomly reduced the number of samples for the agroforestry systems to three because we had only three replicates in primary forest and openland.

We used the additive partitioning method to test for the contribution of spatial variation in species richness per habitat type (beta-spatial) and temporal variation in species richness per habitat type (beta-temporal) to regional gamma-diversity (Lande 1996; Crist and Veech 2006; Gabriel et al. 2006) such that beta-diversity equals gamma-diversity minus alphadiversity. Diversity was partitioned in alpha-diversity (average number of species per plot (=replicate)), spatial beta-diversity (species richness per habitat type minus species richness per plot, averaged per habitat type) and temporal beta-diversity (species richness per habitat type minus species richness per phase, averaged per habitat type). We randomly reduced the number of replicates in the three different agroforestry systems to three. For each alpha, beta-spatial and beta-temporal as response variable, we used one-way ANOVA with habitat type as categorical predictor to test for diversity differences between habitats.

To assess the plant and pollinator community distance between the plots we used the nonmetric multidimensional scaling method (NMDS). Each input matrix consisted of a Bray-Curtis similarity index calculated between each plot.

Statistical analyses were carried out in Statistica (StatSoft, Inc. 2004.), version 7. www. statsoft.com.). The Bray-Curtis similarity index and Michaelis-Menten species estimator were calculated using EstimateS (Colwell, R.K. 2005, version 7.5. Persistent URL: purl.oclc.org/estimate). Residuals were tested for normal distribution and were log transformed if necessary. We used type-I (sequential) sum of squares for each model. We give arithmetic mean \pm standard error in the text.

\section{Results}

In total 1207 bees belonging to 53 native species were caught from flowers (86\%) or during search flight for flowers (14\%). We identified 75 different flowering plant species in all five habitat types, of which 38 species were visited by a bee during transect observations. For the other plant species we can therefore not prove attractiveness for bees and they were not included in the analyses.

Bee species richness and density

The bee community was determined by habitat type and plant density (Table 2a). Bee species richness varied significantly across habitats, with significantly lower bee richness in primary forests $(1.54 \pm 0.27$ species per plot and sampling phase, $n=15)$ compared to 
Table 2 General linear models for the factors that influence bee species richness (a) and density (b)

\begin{tabular}{lcccccc}
\hline & Effect & DF & \multicolumn{1}{c}{ SS } & MS & \multicolumn{1}{l}{$F$} & $P$ \\
\hline (a) Bee species richness & & & & & & \\
Habitat & Fixed & $\mathbf{4}$ & $\mathbf{1 5 . 0 3}$ & $\mathbf{3 . 7 6}$ & $\mathbf{1 4 . 6 6}$ & $<\mathbf{0 . 0 0 1 * * *}$ \\
Phase & Fixed & 3 & 0.03 & 0.01 & 0.05 & 0.99 \\
Climate & Fixed & 1 & 0.01 & 0.01 & 0.04 & 0.84 \\
Plant species richness & Fixed & 1 & 0.04 & 0.04 & 0.16 & 0.69 \\
Plant density & Fixed & $\mathbf{1}$ & $\mathbf{2 . 1 6}$ & $\mathbf{2 . 1 6}$ & $\mathbf{8 . 4 2}$ & $\mathbf{0 . 0 0 6 * *}$ \\
Error & & 50 & 12.81 & 0.26 & & \\
(b) Bee density & & & & & & \\
Habitat & Fixed & $\mathbf{4}$ & $\mathbf{4 1 . 4 6}$ & $\mathbf{1 0 . 3 6}$ & $\mathbf{2 2 . 8 8}$ & $<\mathbf{0 . 0 0 1 * * *}$ \\
Phase & Fixed & 3 & 1.19 & 0.4 & 0.87 & 0.462 \\
Climate & Fixed & 1 & 0.04 & 0.04 & 0.09 & 0.768 \\
Plant species richness & Fixed & 1 & 0.008 & 0.008 & 0.018 & 0.895 \\
Plant density & Fixed & $\mathbf{1}$ & $\mathbf{7 . 8 6}$ & $\mathbf{7 . 8 6}$ & $\mathbf{1 7 . 3 5}$ & $<\mathbf{0 . 0 0 1} * * *$ \\
Error & & 50 & 22.64 & 0.45 & & \\
\hline Bold & & & & &
\end{tabular}

Bold letters indicate significant effects

all other habitat types (open habitat: $9.8 \pm 0.92, n=15$; low-intensity agroforestry: $4.26 \pm 0.53, n=20$; medium-intensity agroforestry: $4.85 \pm 0.49, n=20$; high-intensity agroforestry: $4.45 \pm 0.6, n=20$ ) and significantly higher richness in open habitats compared to low and high-intensity cacao agroforestry systems (Fig. 1). Bee richness increased with increasing density of flowering plants (Fig. 2), whereas sampling phase, climate and plant richness had no significant influence on bee species richness (Table 2a). We found similar results for bee density. Habitat significantly influenced bee density. Primary forest habitats had significantly lower and openland had significantly higher bee densities compared to all other habitats (primary forest $2.62 \pm 0.64$ individuals per plot and sampling phase, $n=15$; low-intensity $8.58 \pm 1.6, n=20$; med-intensity $8.4 \pm 1.28$, $n=20$; high-intensity $9.3 \pm 1.92, n=20$ and openland $43.73 \pm 5.58, n=15$ ). Bee density increased with plant density, whereas sampling phase, climate and plant richness did not influence bee density (Table 2b). Plant density as the only significant continuous predictor was negatively correlated with canopy cover (Fig. 3), but independent of slope and plot height.

\section{Estimated species richness}

The Michaelis-Menten means revealed that all agroforestry systems had higher estimated numbers of species (HIA: 39.1, MIA: 45.4, LIA: 40.8) compared to openland (38.6), when sample size is similar and primary forest had by far the lowest number of species (9.7). Accordingly, the percentage of recorded species per habitat type from estimated number of species was lowest in agroforestry systems (HIA: 64\%, MIA: 57.3\%, LIA: $53.9 \%$ ) compared to openland $(80.2 \%)$ and primary forest $(72.2 \%)$.

Spatiotemporal species turnover

The additive partitioning showed significant differences between the five habitats in terms of alpha-diversity $\left(r^{2}=0.58, F_{4,66}=22.74\right.$, $\left.* * * P<0.001\right)$. Primary forest plots had a 


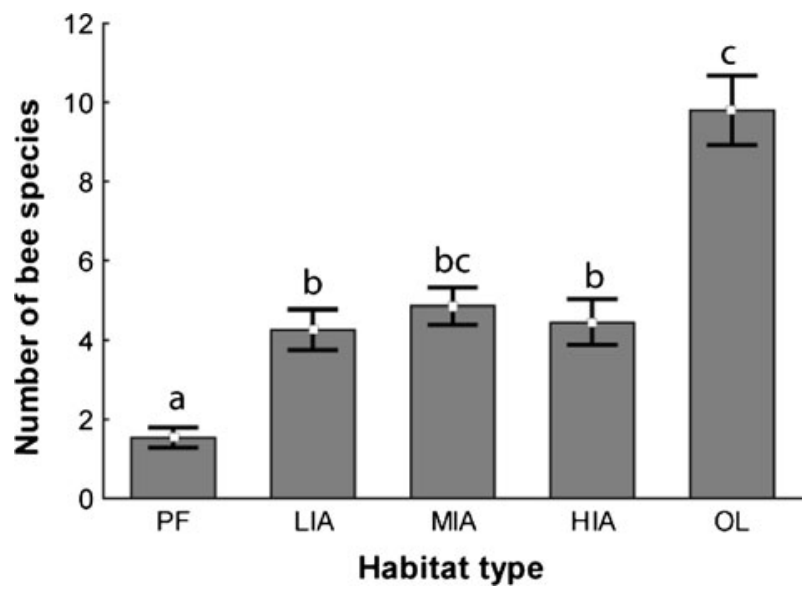

Fig. 1 Bee species richness along a gradient of land-use intensification per plot and phase (habitat codes described in "Methods" section). Arithmetic means and \pm standard error are given. Significant differences between habitat types $(P<0.05)$ are indicated by different letters

Fig. 2 Bee species richness in relation to plant density in the understorey per plot and phase. Bee species richness increases with increasing plant density. Different habitats are represented by different symbols ( $\mathbf{\square}$-OL, $\boldsymbol{\Delta}$-HIA, *-MIA, $\nabla$-LIA, O-PF; habitat codes described in "Methods")

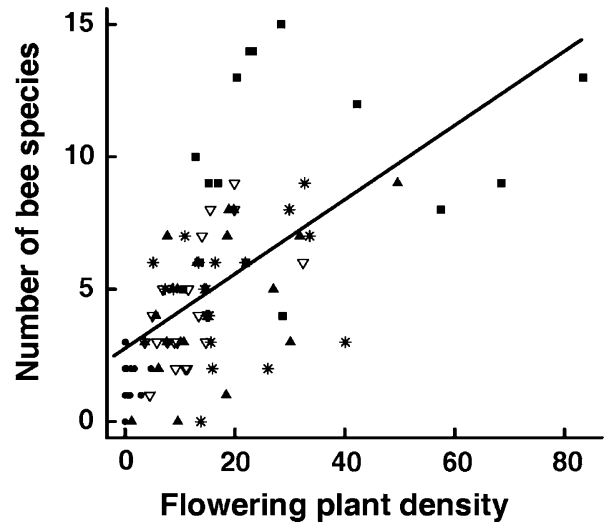

Fig. 3 Influence of canopy cover on plant density in the understorey. Plant density, quantified with an index from 1 to 100 , is decreasing with increasing canopy cover

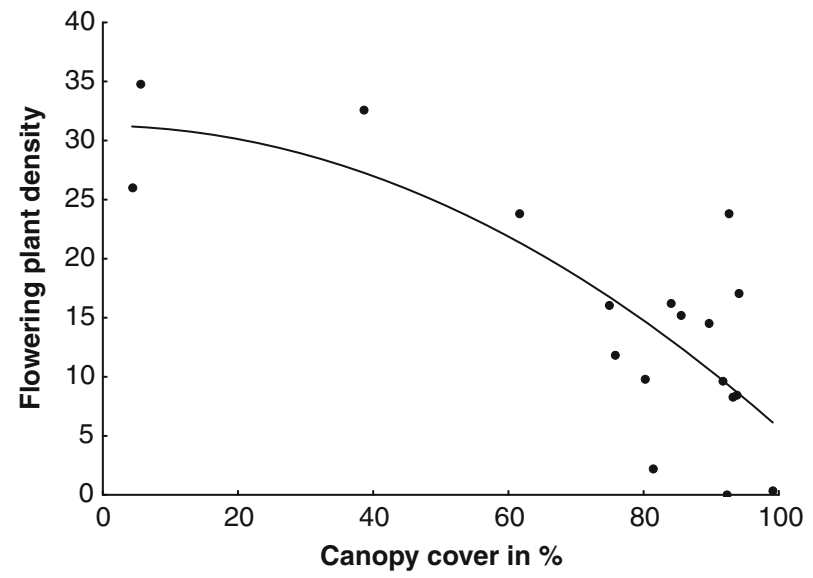




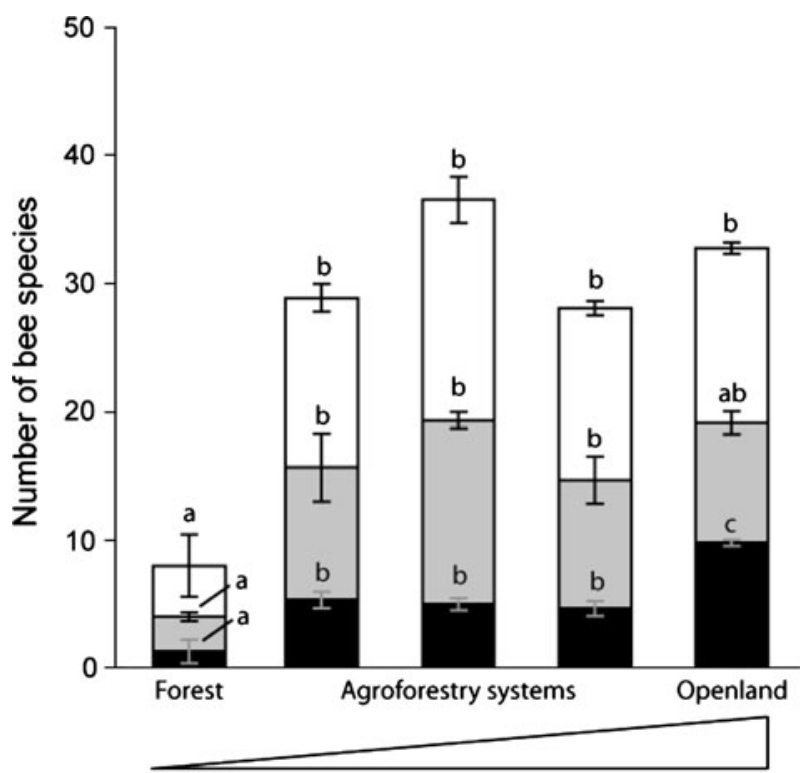

Land-use-intensification gradient

Fig. 4 Additive partitioning of species richness along a land-use intensification gradient with the five habitat types. Black bars showing the alpha-diversity fraction, grey bars the spatial beta-diversity (diversity between replicates) and the white bars the temporal beta-diversity fraction (diversity between phases). Different letters indicate significant differences between diversity levels between each habitat type

lower alpha-diversity and openland had higher alpha-diversity compared to all other habitat types. Spatial beta-diversity (differences between plots of one habitat type) was significantly lower in primary forests compared to all agroforestry systems but not to openland $\left(r^{2}=0.75, F_{4,10}=7.52\right.$, ** $P=0.0046$; Fig. 4). Temporal beta-diversity (differences between phases of one plot) (log transformed) $\left(r^{2}=0.79, F_{4,20}=18.53\right.$, *** $\left.P<0.001\right)$ was significantly lower in primary forest plots compared to all other habitat types (Fig. 4). Multidimensional scaling revealed that bee and plant species composition was formed by habitat type, because species communities were ordered along the two dimensions according to land-use intensity (Fig. 5a, b), whereas low-intensity agroforestry (fine rings) was more similar to primary forest plots than medium and high-intensity agroforestry. Furthermore, the openland plots were more clustered than all other habitat types and especially the bee community in openland strongly differed from all other habitat types.

\section{Discussion}

Openland plots had highest bee species richness and abundance compared to agroforestry and forest plots, whereas agroforestry management type did not affect bee species richness and abundance. Even though forested habitats are closer to the natural vegetation type (primary rainforest) than un-forested habitats they do not appear to be significant habitats for maintaining high species richness of bees (already shown by Liow et al. 2001; Winfree et al. 2007). We show that managed habitats provided better food supply in the understorey than natural habitat due to high flower density (Potts et al. 2006), which was negatively 

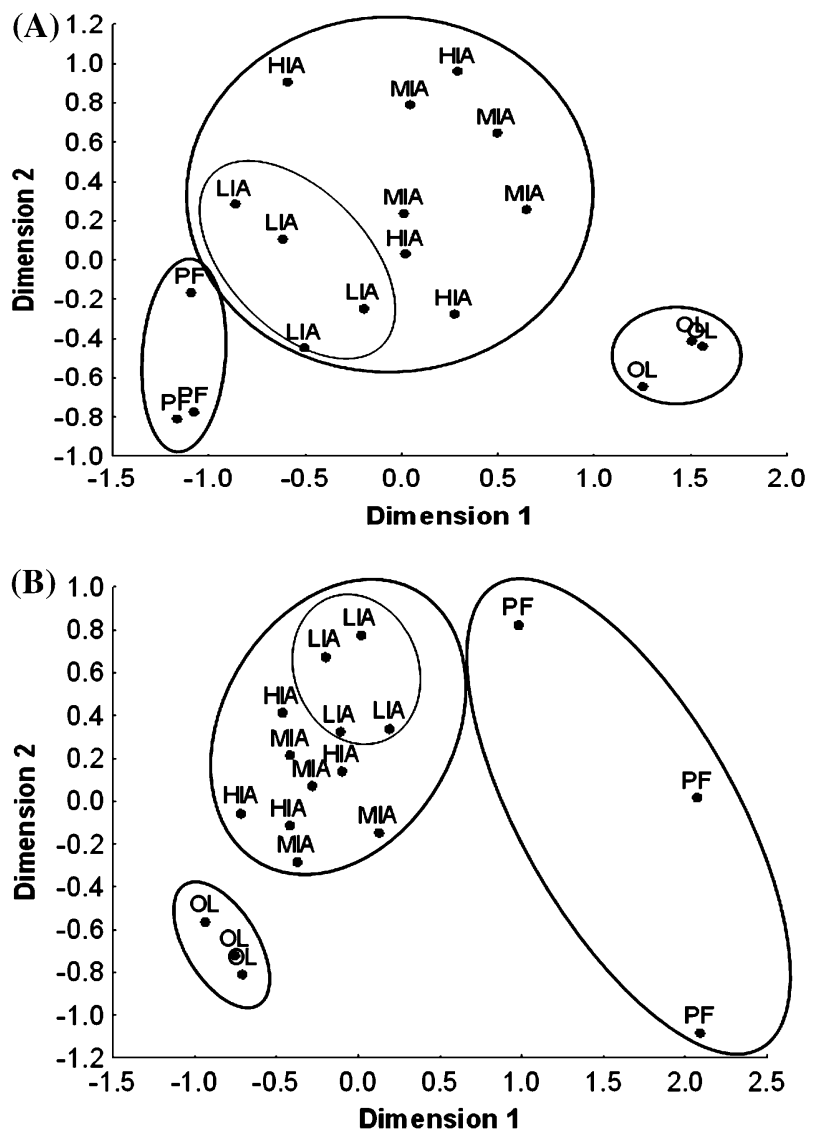

Fig. 5 Multidimensional scaling of $\mathbf{a}$ bee and $\mathbf{b}$ plant species communities. Points represent the species composition and density of a certain habitat calculated with the Bray-Curtis similarity index ( $P F$ primary forest, LIA low-intensity agroforestry, MIA medium-intensity agroforestry, HIA high-intensity agroforestry, $O L$ openland) with four and three replicates, respectively, shown by number of points. Larger distances between the points indicate larger distances in species compositions. Rings were used to group primary forests, agroforestry systems and openland. Fine rings comprise the low-intensity agroforestry plots to visualize the vicinity of species composition to primary forest

correlated with canopy cover, a relation already found in other tropical forests (Bruna and Ribeiro 2005) and conifer stands (Lindh 2005), resulting in higher bee richness and density. Canopy cover in low-intensity agroforestry systems was very similar to primary forests, but flowering plant density was higher and thus bee richness and abundance were also higher. However, we sampled the herb layer and the understorey of the forested plots, and sampling the canopy, in particular in the primary forest, may change the picture as shown for trap nesting bees and wasps in temperate forests (Sobek et al. 2009).

Openland had a significantly higher alpha but not beta-diversity than all other habitat types. Agroforestry systems had a higher spatial beta-diversity compared to primary forests, but not openland. High spatial heterogeneity due to different management practices appeared to be responsible for increased beta-diversity in agroforestry systems compared to more homogeneous openland plots. The multidimensional scaling supports this finding in that bee communities of openland plots were highly clustered, while forested habitats 
covered a larger variety of species compositions. Hence, agroforestry systems may maintain high regional species richness due to high management diversity and mediumintensity disturbance, enhancing floral abundance and spatiotemporal habitat heterogeneity. Canopy disturbances in primary forests occur frequently due to tree fall gaps, resulting in increased herbaceous vegetation density and insect richness compared to interior forest (Dirzo et al. 1992; Bruna and Ribeiro 2005; Horn et al. 2005; Wunderle et al. 2005). Anthropogenic disturbances in agroforestry systems, such as opening of the canopy (Liow et al. 2001; Winfree et al. 2007), appeared to simulate and promote the positive effect of natural tree fall on the plant, and thereby, the bee community in our study.

Forested habitats offer nesting sites for many bee species (Klein et al. 2003b; Brosi et al. 2007; Brosi et al. 2008), while openland provides better food resources in the herb layer, but bees are known to often bridge different habitats providing different resources (Tscharntke et al. 2005a). Therefore, bee diversity of human-dominated habitats may often depend on large areas of natural habitats providing nesting resources (Steffan-Dewenter et al. 2002), but floral resources may be similarly or even more important (Westphal et al. 2003; Jha and Vandermeer 2009). In conclusion, the different habitat types strongly differed in their relative contribution to the bee community. The land-use systems in the studied human dominated tropical landscape strongly increased local and regional pollinator species richness through enhanced heterogeneity of the landscape. Local species richness was highest in openland, but the high beta-diversity of agroforestry systems levelled off this difference, resulting in similar gamma-diversity. However, farmers recently tend to remove shade trees in coffee and cacao agroforestry, thereby simplifying these systems (Perfecto et al. 1996; Steffan-Dewenter et al. 2007). Such reduction of heterogeneity in tropical landscapes will further reduce overall biodiversity and associated ecological services such as pollination of wild and crop plants provided by the native bee communities.

Acknowledgments We thank Andrea Holzschuh and Owen T. Lewis for valuable suggestions on the manuscript, Stephan Risch, Leverkusen (Germany) for species identification of bees and Ramadhanil Pitopang, Palu (Indonesia) for identification of herbaceous plant species. We thank the Deutsche Forschungsgemeinschaft (DFG) for financing the Collaborative Research Centre STORMA (SFB 552), LIPI for the research permit and Damayanti Buchori for collaboration. We are grateful to Daniel Stietenroth, Wolfram Lorenz, Adam Malik and Surya Tarigan from the STORMA coordination offices in Göttingen, Palu and Bogor for organisational support, field and lab assistants in Toro and Palu and the plot owners for the patience to let us enter their land.

Open Access This article is distributed under the terms of the Creative Commons Attribution Noncommercial License which permits any noncommercial use, distribution, and reproduction in any medium, provided the original author(s) and source are credited.

\section{References}

Brosi BJ, Daily GC, Ehrlich PR (2007) Bee community shifts with landscape context in a tropical countryside. Ecol Appl 117:418-430

Brosi BJ, Daily GC, Shih TM et al (2008) The effects of forest fragmentation on bee communities in tropical countryside. J Appl Ecol 45:773-783

Bruna EM, Ribeiro MBN (2005) The compensatory responses of an understory herb to experimental damage are habitat-dependent. Am J Bot 92:2101-2106

Cairns CE, Villanueva-Gutierrez R, Koptur S et al (2005) Bee populations, forest disturbance, and africanization in Mexico. Biotropica 37:686-692 
Castelletta M, Sodhi NS, Subaraj R (2000) Heavy extinctions of forest avifauna in Singapore: lessons for biodiversity conservation in Southeast Asia. Conserv Biol 14:1870-1880

Colwell RK, Coddington JA (1994) Estimating terrestrial biodiversity through extrapolation. In: Hawksworth DL (ed) Biodiversity: measurement and estimation. Royal Society, London, pp 101-118

Crist TO, Veech JA (2006) Additive partitioning of rarefaction curves and species area relationships: unifying alpha, beta, and gamma diversity with sample size and habitat area. Ecol Lett 9:923-932

Daily GC (2001) Ecological forecasts. Nature 411:245

Daily GC, Ceballos G, Pacheco J et al (2003) Countryside biogeography of neotropical mammals: conservation opportunities in agricultural landscapes of Costa Rica. Conserv Biol 17:1814-1826

Dietsch TV, Perfecto I, Greenberg R (2007) Avian foraging behavior in two different types of coffee agroecosystem in Chiapas, Mexico. Biotropica 39:232-240

Dirzo R, Horvitz CC, Quevedo H et al (1992) The effects of gap size and age on the understorey herb community of a tropical Mexican rain-forest. J Ecol 80:809-822

Gabriel D, Roschewitz I, Tscharntke T et al (2006) Beta-diversity at different spatial scales: plant communities in organic and conventional agriculture. Ecol Appl 16:2011-2021

Giri C, Defourny P, Shrestha S (2003) Land cover characterization and mapping of continental Southeast Asia using multi-resolution satellite sensor data. Int J Remote Sens 24:4181-4196

Groombridge B (1992) Global biodiversity: status of the earth's living resources. Chapman \& Hall, London, UK

Horn S, Hanula JL, Ulyshen MD (2005) Abundance of green tree frogs and insects in artificial canopy gaps in a bottomland hardwood forest. Am Midl Nat 153:321-326

Jha S, Vandermeer JH (2009) Contrasting bee foraging in response to resource scale and local habitat management. Oikos 118:1174-1180

Kearns CA, Inouye DW, Waser NM (1998) Endangered mutualisms: the conservation of plant-pollinator interactions. Annu Rev Ecol Syst 29:83-112

Klein AM, Steffan-Dewenter I, Buchori D et al (2002) Effects of land-use intensity in tropical agroforestry systems on coffee flower-visiting and trap nesting bees and wasps. Conserv Biol 16:1003-1014

Klein AM, Steffan-Dewenter I, Tscharntke T (2003a) Fruit set of highland coffee increases with the diversity of pollinating bees. Proc R Soc Lond B Biol Sci 270:955-961

Klein AM, Steffan-Dewenter I, Tscharntke T (2003b) Pollination of Coffea canephora in relation to local and regional agroforestry management. J Appl Ecol 40:837-845

Klein AM, Vaissière BE, Cane JH et al (2007) Importance of pollinators in changing landscapes for world crops. Proc R Soc Lond B Biol Sci 274:303-313

Kremen C, Williams NM, Thorp RW (2002) Crop pollination from native bees at risk from agricultural intensification. P Natl Acad Sci USA 99:16812-16816

Kremen C, Williams NM, Bugg RL et al (2004) The area requirements of an ecosystem service: crop pollination by native bee communities in California. Ecol Lett 7:1109-1119

Lande R (1996) Statistics and partitioning of species diversity, and similarity among multiple communities. Oikos 76:5-13

Lindh BC (2005) Effects of conifer basal area on understory herb presence, abundance, and flowering in a second-growth Douglas-fir forest. Can J For Res 35:938-948

Liow LH, Sodhi NS, Elmqvist T (2001) Bee diversity along a disturbance gradient in tropical lowland forests of south-east Asia. J Appl Ecol 38:180-192

Millennium Ecosystem Assessment (2005) In: Mace G, Masundire H, Baillie J (eds) Ecosystems and human well-being: current state and trends, Chap 4. Island Press, Washington, DC

Perfecto I, Rice RA, Greenberg R et al (1996) Shade coffee: a disappearing refuge for biodiversity. Bioscience 46:598-608

Perfecto I, Armbrecht I, Philpott SM (2007) Shaded coffee and the stability of rainforest margins in northern Latin America. In: Tscharntke T, Leuschner C, Zeller M, Guhadja E, Bidin A et al (eds) Stability of tropical rainforest margins: linking ecological, economic and social constraints of land use and conservation. Springer, Berlin, pp 227-264

Potts SG, Petanidou T, Roberts S et al (2006) Plant pollinator biodiversity and pollination services in a complex Mediterranean landscape. Biol Conserv 129:519-529

Ricketts TH, Daily GC, Ehrlich PR et al (2001) Countryside biogeography of moths in a fragmented landscape: biodiversity in native and agricultural habitats. Conserv Biol 15:378-388

Ricketts TH, Regetz J, Steffan-Dewenter I et al (2008) Landscape effects on crop pollination services: are there general patterns? Ecol Lett 11:499-515

Sobek S, Tscharntke T, Scherber C et al (2009) Canopy vs. understory: does tree diversity affect bee and wasp communities and their natural enemies across forest strata? For Ecol Manag 258:609-615 
Steffan-Dewenter I, Munzenberg U, Burger C et al (2002) Scale dependent effects of landscape context on three pollinator guilds. Ecology 83:1421-1432

Steffan-Dewenter I, Kessler M, Barkmann J et al (2007) Tradeoffs between income, biodiversity, and ecosystem functioning during tropical rainforest conversion and agroforestry intensification. PNAS 104:4973-4978

Tscharntke T, Klein AM, Kruess A et al (2005a) Landscape perspectives on agricultural intensification and biodiversity-ecosystem service management. Ecol Lett 8:857-874

Tscharntke T, Rand TA, Bianchi FJJA et al (2005b) The landscape context of trophic interactions: insect spillover across the crop-noncrop interface. Ann Zool Fenn 42:421-432

Tylianakis JM, Klein AM, Lozada T et al (2006) Spatial scale of observation affects alpha, beta and gamma diversity of cavity-nesting bees and wasps across a tropical land-use gradient. J Biogeogr 33:12951304

Westphal C, Steffan-Dewenter I, Tscharntke T (2003) Mass flowering crops enhance pollinator densities at a landscape scale. Ecol Lett 6:961-965

Winfree R, Griswold T, Kremen C (2007) Effect of human disturbance on bee communities in a forested ecosystem. Conserv Biol 21:213-223

Wunderle JM, Willig MR, Henriques LMP (2005) Avian distribution in treefall gaps and understorey of terra firme forest in the lowland Amazon. Ibis 147:109-129 